\title{
Revisão de terapias no aumento de resposta da atividade melanocítica para repigmentação cutânea de portadores com vitiligo
}

\author{
Review of therapies to increase the response of melanocytic activity to skin repigmentation of \\ patients with vitiligo \\ Revisión de terapias para incrementar la respuesta de la actividad melanocítica en la \\ repigmentación cutánea de pacientes con vitiligo
}

Recebido: 16/08/2021 | Revisado: 26/08/2021 | Aceito: 29/08/2021 | Publicado: 30/08/2021

Karla Mileny Monteiro Ventura ORCID: https://orcid.org/0000-0001-9185-6178 Escola Superior da Amazônia, Brasil E-mail: karlav2017@gmail.com

Jonathan Potiguara de Miranda ORCID: https://orcid.org/0000-0002-4079-2968 Escola Superior da Amazônia, Brasil

E-mail: jonathanpotiguara10@gmail.com

Elaine Queiroz da Costa

ORCID: https://orcid.org/0000-0001-6260-0317 Escola Superior da Amazônia, Brasil E-mail: 05081985e@gmail.com

Diego da Silva Santana

ORCID: https://orcid.org/0000-0002-2065-0073 Escola Superior da Amazônia, Brasil E-mail: diegosil10santana@gmail.com

Juan Gonzalo Bardález Rivera ORCID: https://orcid.org/0000-0003-1737-6947 Escola Superior da Amazônia, Brasil E-mail: jgrivera@bol.com.br

Russany Silva da Costa ORCID: https://orcid.org/0000-0002-2705-1591 Universidade Federal do Pará, Brasil E-mail:russany.costa@gmail.com

\begin{abstract}
Resumo
O vitiligo é uma doença imunológica caracterizada pela despigmentação da pele, causando manchas acrômicas, sem predileção por sexo ou etnia. Ademais, pode provocar alterações emocionais, comprometimento da autoestima e nas relações sociais do indivíduo. Assim, esse trabalho propõe uma revisão sistemática da literatura objetivando evidenciar a eficiência de protocolos de terapias disponíveis para o vitiligo e sua correlação. Metodologia: Trata-se de um estudo de revisão sistemática, de caráter descritivo, retrospectivo realizado a partir de pesquisas nas principais bases de dados acadêmicas. Ex. PubMed, Lilacs e Periódicos Capes, etc. Assim, fez-se buscas livres de palavras relacionadas ao tema proposto: tratamento do vitiligo e associações, excluindo os trabalhos que mostraram ineficiência (baixo percentual de repigmentação) quando comparada aos tratamentos convencionais. Nesse sentido, foram encontrados 35 artigos científicos e 27 terapias distintas para o tratamento de vitiligo. Resultados e Discussão: Tais terapias foram divididas em 4 categorias: corticosteroides, fotobiomodulação, imunossupressores e antioxidantes. O uso de corticosteroides mostrou-se eficaz na estabilização da doença. Das fototerapias, a kelina agiu em $70 \%$ dos casos de repigmentação. Já os imunossupressores JAK demonstram repigmentação total ou acima de $75 \%$. E os antioxidantes mostraram eficácia de $67 \%$ de repigmentação, com destaque para a espécie Polypodium leucotomos e Brosimum gaudichaudii com alto índice de repigmentação completa, principalmente quando associado a radiação UVB. Já o tratamento com Ginko biloba teve $80 \%$ de estabilização da doença. Conclusão: Os protocolos mostraram que a associação das fototerapias com terapias convencionais e inovadoras são mais frequentemente eficazes no tratamento do vitiligo, potencializando os resultados.
\end{abstract}

Palavras-chave: Repigmentação; Vitiligo; Fototerapia; Mama-cadela; Corticosteroides.

\section{Abstract}

Vitiligo is an immunological disease characterized by depigmentation of the skin, causing achromic spots, with no predilection for sex or ethnicity. Furthermore, it can cause emotional changes, compromise the individual's self-esteem and social relationships. Thus, this work proposes a systematic review of the literature aiming to evidence the efficiency 
of available therapy protocols for vitiligo and their correlation. Methodology: This is a systematic review study, descriptive and retrospective, carried out based on research in the main academic databases. Ex. PubMed, Lilacs and Capes Periodics, etc. Thus, free searches were made for words related to the proposed theme: vitiligo treatment and this associations, excluding studies that showed inefficiency (low percentage of repigmentation) when compared to conventional treatments. In this sense, 35 scientific articles and 27 different therapies for the treatment of vitiligo were found. Results and Discussion: Such therapies were divided into 4 categories: corticosteroids, photobiomodulation, immunosuppressants and antioxidants. The use of corticosteroids proved to be effective in stabilizing the disease. Phototherapies added kelina acted in $70 \%$ of the cases of repigmentation. JAK immunosuppressants demonstrated a total of repigmentation above $75 \%$. And the antioxidants showed $67 \%$ efficacy of repigmentation, with emphasis on the species Polypodium leucotomos and Brosimum gaudichaudii with a high index of complete repigmentation, especially when associated with UVB radiation. Treatment with Ginko biloba had 80\% disease stabilization. Conclusion: The protocols showed that the association of phototherapies with conventional and innovative therapies are more often effective in the treatment of vitiligo, enhancing the results.

Keywords: Repigmentation; Vitiligo; Phototherapy; Mama-cadela; Corticosteroids.

\section{Resumen}

El vitiligo es una enfermedad inmunológica caracterizada por la despigmentación de la piel, provocando manchas acrómicas, sin predilección por el sexo ni la etnia. Además, puede provocar cambios emocionales, comprometer la autoestima y las relaciones sociales del individuo. Así, este trabajo propone una revisión sistemática de la literatura con el objetivo de evidenciar la eficacia de los protocolos terapéuticos disponibles para el vitiligo y su correlación. Metodología: Se trata de un estudio de revisión sistemática, descriptiva, retrospectiva, realizada a partir de investigaciones en las principales bases de datos académicas. Ej. PubMed, Revistas Lilacs y Capes, etc. Se realizaron búsquedas gratuitas de palabras relacionadas con la temática propuesta: tratamiento y asociaciones del vitíligo, excluyendo los estudios que mostraran ineficiencia (bajo porcentaje de repigmentación) en comparación con los tratamientos convencionales. Se encontraron 35 artículos científicos y 27 terapias diferentes para el tratamiento del vitiligo. Resultados y Discusión: Dichas terapias se dividieron en 4 categorías: corticosteroides, fotobiomodulación, inmunosupresores y antioxidantes. El uso de corticosteroides demostró ser eficaz para estabilizar la enfermedad. De las fototerapias, kelina actuó en el $70 \%$ de los casos de repigmentación. Los inmunosupresores JAK demuestran repigmentación total o superior al 75\%. Y los antioxidantes mostraron una eficacia de repigmentación del $67 \%$, con énfasis en las especies Polypodium leucotomos y Brosimum gaudichaudii con un alto índice de repigmentación completa, especialmente cuando se asocia con radiación UVB. El tratamiento con Ginko biloba logró una estabilización de la enfermedad del 80\%. Conclusión: Los protocolos mostraron que la asociación de fototerapias con terapias convencionales e innovadoras son más a menudo efectivas en el tratamiento del vitiligo, mejorando los resultados.

Palabras clave: Repigmentación; Vitiligo; Fototerapia; Mamá-perra; Corticosteroides.

\section{Introdução}

O vitiligo é uma doença carcaterizada pela perda da coloração da pele. As lesões formam-se devido à diminuição ou à ausência de melanócitos, que são as células responsáveis pela sintése da melanina, pigmento que dá cor à pele, nos locais afetados. A causa do vitiligo ainda não está totalmente estabelecido, mas fenômenos autoimunes parecem estar associados. Além disso, alterações ou traumas emocionais podem estar entre os fatores que desencadeiam e/ou agravam a doença (Sociedade Brasileira de Dermatologia, 2021). O vitiligo afeta um a dois de cada 100 pessoas e um quinto dos afetados têm algum membro da família com a patologia. (Souza, 2017). O grau de redução do pigmento difere entre indivíduos, podendo variar de acordo com o tom da pele, o grau de estresse e ansiedade, resultando em diferentes tons de despigmentação.

Inicialmente surgem manchas hipocrômicas, em seguida, acrômicas e marfínicas de limites nítidos, normalmente com bordas hiperpigmentadas, aparência e proporções variáveis não pruriginosas. Com tendência à distribuição simétrica e preferência por áreas maleolares, punhos, face, anterolateral das pernas, dorso das mãos, dedos, axilas, pescoço e genitália; no couro cabeludo há poliose (perda da melanina ciliar). É raro nas palmas das mãos e plantas dos pés, porém é frequente nas regiões perioral e periorbirtária, podendo atingir os olhos. Em cerca de 7\% dos portadores, o vitiligo gera uma uveíte subclínica e eventualmente lesão na mácula (Nunes \& Esser, 2011).

Nos últimos anos foram propostos diferentes sistemas de classificação clínica da doença, porque nem todos os casos se comportam da mesma forma, ou têm as mesmas características, as quais dependem da distribuição e do tamanho da superfície atingida, sendo divididas em localizada, generalizada e universal (Nunes \& Esser, 2011). Alguns autores classificam o vitiligo 
como Vitiligo Não Segmentar (VNS): grupo composto pelas formas focal, mucoso, acrofacial, generalizada ou comum e universal, e Vitiligo Segmentar (VS). O vitiligo não segmentar inicia em qualquer idade, com aparecimento de novas lesões no decorrer da vida do paciente, caracteriza-se por máculas distribuídas simetricamente, sendo a forma mais comum, normalmente de evolução instável e crônica. Enquanto o vitiligo segmentar pode ser uni, bi ou multissegmentar. A forma unissegmentar é a mais comum e consiste na presença de uma ou mais manchas brancas em um lado do corpo, geralmente respeitando a linha média corporal, com envolvimento dos pelos (leucotríquia) e rápido início do quadro (Sousa, 2017).

Segundo Balaban et al. (2011), o portador de doenças dermatológicas crônicas pode sofrer fortes consequências sociais e emocionais provocadas principalmente pela visibilidade das condições do paciente. Nesse contexto, os pacientes com vitiligo geralmente apresentam uma autoimagem negativa e baixa autoestima, o que gera um prejuízo na vida social do indivíduo, principalmente os do sexo feminino, adolescentes e adultos jovens, conforme afirmam Padilla-España, Ramírez-López \& Fernández-Sánchez (2014). Como consequência desse problema, Cupertino, Niemeyer-Corbellini \& Ramos-E-Silva (2017) evidenciam a associação entre o vitiligo e o desenvolvimento de doenças psiquiátricas, em especial a depressão.

Ademais, essa dermatose apresenta frequência variável de $0,38 \%$ a $2,9 \%$ da população mundial e se diversifica conforme a região estudada (Birlea, Fain \& Spritz, 2008). No Brasil, um estudo estimou uma prevalência de 0,57\% de indivíduos com vitiligo (SBD, 2017). Porém, é provável que existam mais de um milhão de brasileiros com esse diagnóstico. Assim, a média de idade de início da doença é em torno da segunda até a terceira década de vida (Barona et al., 1995). Em 25\% dos doentes se inicia antes dos 10 anos, em 50\% a perda de pigmentos começa antes dos 20 anos, e em cerca de $80 \%$ começa antes dos 30 anos de idade.

Apesar de todas as diretrizes apontarem para um problema unicamente estético, Ezzedine et al. (2015) afirmam que o vitiligo não é somente uma doença dermatólogica, portanto, tratamentos podem e devem ser oferecidos aos pacientes.

Atualmente, as opções de tratamento disponíveis para os pacientes com vitiligo têm eficácia limitada. Portanto, os critérios para avaliar a resposta ao tratamento do vitiligo incluem: cessação da disseminação da mancha, o surgimento da repigmentação da pele e qualidade de vida geral durante o tratamento (Whitton et al., 2015)

Desse modo, é importante ressaltar que ainda não há cura ou qualquer método eficaz de impedir a propagação da doença. Por isso, o tratamento do vitiligo é frequentemente difícil e frustrante, tanto para o paciente como para o médico. Nesse sentido, o tratamento atual para o vitiligo se baseia no uso de corticosteroides, de inibidores de Calcineurina, de Calcipotriol, de luz ultravioleta (UVA e UVB) e laserterapia, sendo essa última, uma modalidade que ganhou bastante popularidade na última década (Cunha et al., 2017).

Gonçalves (2019) afirma que grande parte desses tratamentos vêm sendo empregados há anos de forma individualizada, mas, alerta que existe uma tendência atual em utilizar combinações de duas ou mais terapias visando a estagnação e a repigmentação das lesões do vitiligo de maneira rápida, e com o menor número possível de efeitos colaterais.

Nesse contexto, esse trabalho propõe uma revisão sistemática da literatura sobre os protocolos de terapias disponíveis para o vitiligo e verifica a correlação entre elas. Nesse sentido, pretende ser um trabalho norteador às pesquisas experimentais visando fornecer informações que direcionem aos melhores resultados na terapia do vitiligo, principalmente nas terapias combinadas, apresentando os melhores resultados em relação as monoterapias, e aquelas que proporcionam interação com diferentes aspectos patogênicos da doença, diminuindo, assim, o tempo de tratamento e os efeitos colaterais aos pacientes. Ademais, permitindo uma maior adesão do paciente ao tratamento, e consequentemente melhora nos resultados das diversas técnicas empregadas. 


\section{Metodologia}

Esse trabalho trata-se de um estudo de revisão sistemática de literatura de caráter descritivo e retrospectivo (Estrela, 2018), baseado em um método específico de revisão que sumariza estudos já concluídos, para prover uma maior compreensão, sobre um fenômeno específico ou problema de saúde, realizado a partir de levantamento bibliográfico de bases de dados online, através do Scientific Eletronic Libray Online (Scielo), U.S National Library of Medicine and the National Instutes Health (PubMed), Literatura Latino Americana e do Caribe em Ciências da Saúde (Lilacs), Medical Literature Analysis and Retrieval System Online (Medline) e Periódicos da Coordenação de Aperfeiçoamento de Pessoal de Nível Superior (Capes), os quais contemplou os artigos mais recentes. Entretanto, a pesquisa não se delimitou a um período específico, pois as terapias utilizadas atualmente já vêm de estudos mais antigos e as novas propostas estabelecem novas diretrizes de tratamento, haja vista que nem todas estão consolidadas no mercado e vem sendo aplicadas na prática farmacêutica.

Como critério de inclusão, buscou-se pesquisas que se enquadram na temática, que foi apresentar os protocolos utilizados na abordagem clínica do vitiligo e os estudos que comprovem estatisticamente sua eficiência. $\mathrm{O}$ critério de seleção levou em consideração quaisquer trabalhos, como artigo científico, monografia, dissertação de mestrado e tese de doutorado, publicados nos idiomas, português, italiano, espanhol e inglês que apresentaram protocolos para abordagem clínica do vitiligo. Para facilitar a pesquisa, optou-se por realizar a busca, por combinação de termos que conectassem a palavra vitiligo à terapias, tratamentos, repigmentação, fototerapias, corticosteroides, antioxidantes e imunossupressores.

Assim, utilizaou-se como critérios de exclusão, os trabalhos que não abordaram a temática proposta, ou seja, que mostraram ineficiência (baixo percentual de repigmentação) comparada aos tratamentos convencionais e como critérios de inclusão foram utilizados os trabalhos que abordaram as terapias repigmentantes, terapias visando estagnação da mancha e terapias inovadoras para o vitiligo.

Ao finalizar as pesquisas em cada base, as referências duplicadas foram excluídas e as referências que não mostraram efetividade diante dos tratamentos convencionais e não apresentaram resultados relevantes foram desconsideradas.

\section{Resultados e Discussão}

A Figura 1 apresenta um fluxograma de organização da pesquisa com as principais decisões tomadas e a classificação que ocorreu durante o processo de busca pelos principais artigos que colaborassem com uma perspectiva mais abrangente das terapias utilizadas no tratamento do vitiligo. A pesquisa rendeu a leitura de 35 artigos completos publicados em diferentes plataformas científicas.

Assim, conforme a Figura 1 o processo de revisão bibliográfica se iniciou com a busca nas bibliotecas digitais ou bancos de dados digitais de artigos científicos (Lilacs, Scielo, Pubmed, Medline, Capes, etc.) de palavras-chave que vinculassem vitiligo à terapias, tratamentos e repigmentação.

Apesar de as pesquisas direcionarem à variadas vertentes de tratamento, pôde-se observar, com frequência o aparecimento das fototerapias combinadas a outros tipos de tratamento. As principais pesquisas encontradas relacionaram o uso de corticosteroides, imunossupressores, antioxidantes e fototerapias, porém se observou que entre as pesquisas mais recentes estão aquelas que estudaram os efeitos dos imunossupressores em associação às fototerapias para a repigmentação da pele em pacientes com vitiligo. 
Figura 1. Fluxograma de processos da revisão da literatura.

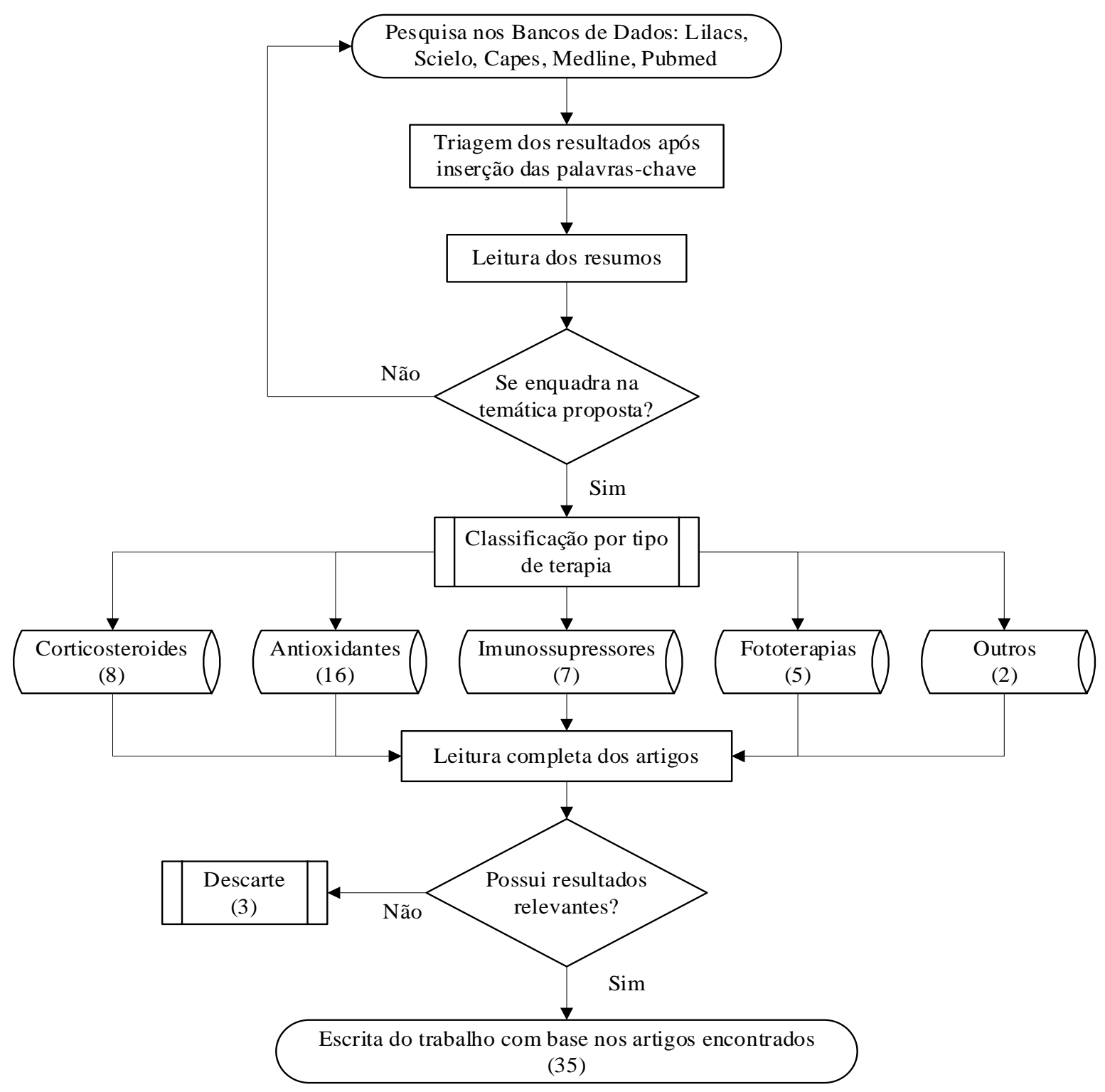

Fonte: Autores.

A apresentação dos resultados nos tópicos subsequentes consistiu em quadros, evidenciando as principais metodologias, resultados e efeitos adversos de cada estudo encontrado, indicando a autoria de cada pesquisa relatada. Nesse sentido, permitiu melhor discutir as diferentes metodologias que cada autor utilizou para representar os resultados de repigmentação obtidos, levando-se em conta os fatores como dose, duração de tratamento, tipo de vitiligo tratado, entre outros, os quais são fundamentais para realizar a correlação dos resultados.

Vale notar também, que cada autor adotou seu procedimento de pesquisa, portanto, substancialmente, não há como fazer uso comparativo dos resultados apenas pela efetividade do tratamento, pois o que é revelado de resultado só pode ser comparado embasado na utilização da mesma metodologia. Nesse caso, quando é proposto pelo autor um comparativo entre diferentes terapias, o mesmo já traça sua pesquisa e faz sua consideração em relação aos resultados encontrados.

\subsection{Corticosteroides}

O Quadro 1 apresenta as principais pesquisas relacionadas ao uso de corticosteroides no tratamento do vitiligo, na qual se observa o uso frequente de metilprednisolona, dexamentasona, minociclina, prednisona e betametasona. 
Quadro 1. Estudos de corticosteroides e terapias combinadas para controle da atividade do vitiligo.

\begin{tabular}{|c|c|c|c|}
\hline Autor & $\begin{array}{l}\text { Modalidade/ } \\
\text { dose }\end{array}$ & $\mathrm{N}^{0}$ de pacientes & $\begin{array}{l}\text { Repigmentação(R) } \\
\text { Estabilização (E) }\end{array}$ \\
\hline $\begin{array}{l}\text { (Kanwar, } \\
\text { Mahajan \& Parsad, } \\
\text { 2013) }\end{array}$ & $\begin{array}{l}\text { Dexametasona } \\
2,5 \mathrm{mg}\end{array}$ & $\begin{array}{c}\mathrm{T}=440 \\
408 \\
50 \text { dos } 408 \text { pacientes }\end{array}$ & $\begin{array}{l}\text { 98\% estabilização da } \\
\text { doença (E) }\end{array}$ \\
\hline $\begin{array}{l}\text { (Singh et al., } \\
\text { 2014) }\end{array}$ & 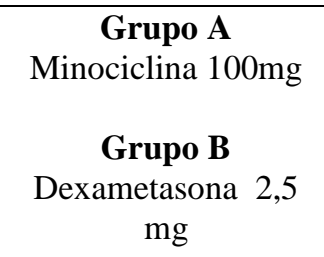 & 50 & $\begin{array}{c}4,0 \text { para } 1,64 \pm 0,86-p \\
<0,001(E) \\
4,0 \text { pra } 1,68 \pm 0,69-p \\
<0,001(E)\end{array}$ \\
\hline (Lee et al., 2016) & $\begin{array}{l}\text { Metilprednisolona de } \\
0,5 \mathrm{mg}+\text { UVB-NB* }\end{array}$ & $\begin{array}{c}\mathrm{T}=32 \\
19 \\
13\end{array}$ & $\begin{array}{l}>25 \%(\mathrm{R}) \\
>50 \%(\mathrm{R})\end{array}$ \\
\hline $\begin{array}{l}\text { (Tovar -Garza } \\
\text { et al., 2019) }\end{array}$ & $\begin{array}{c}\text { Grupo A } \\
\text { Dexametasona + } \\
\text { UVB-NB* e creme de } \\
\text { clobetasol } 0,05 \% \\
\\
\text { Grupo B } \\
\text { Dexametasona + } \\
\text { UVB-NB* e creme de } \\
\text { clobetasol } 0,05 \%\end{array}$ & $\begin{array}{c}\mathrm{T}=25 \\
23 \text { dos } 25 \text { pacientes } \\
\mathrm{T}=15 \\
8 \text { dos } 15 \text { pacientes }\end{array}$ & 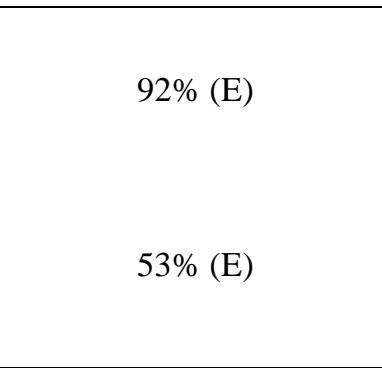 \\
\hline $\begin{array}{l}\text { (Patra et al., } \\
\text { 2019) }\end{array}$ & $\begin{array}{c}\text { Grupo A } \\
\text { Betametasona 5mg } \\
\text { Grupo B } \\
\text { Azatioprina 50mg }\end{array}$ & $\begin{array}{c}\mathrm{T}=55 \\
28\end{array}$ & $\begin{array}{l}2 \text { participantes do grupo } \\
\text { A alcançaram uma } \\
\text { repigmentação de } 20 \% \text {, } \\
\text { outros dois de } 10 \text { a } 20 \% \\
\text { de repigmentação e nove } \\
\text { de } 5 \text { a } 10 \% \text {. } \\
\text { No grupo B apenas } 2 \\
\text { pacientes alcançaram uma } \\
\text { repigmentação de } 10 \text { a } \\
20 \% \text {. }\end{array}$ \\
\hline
\end{tabular}

* UVB-NB: ultravioleta B de banda estreita. Fonte: Autores.

O estudo retrospectivo conduzido por Kanwar, Mahajan e Parsad (2013) avaliou a eficácia de terapias por meio de Minipulsos orais (MPO) nos pacientes que apresentaram vitiligo instável progressivo e que receberam 2,5 mg de dexametasona por dois dias consecutivos por semana, entre 2006 e 2010, e revelou uma alta taxa de estabilização da doença (98\%). Os autores inferiram que a terapia é uma boa opção para interromper a evolução do vitiligo, já que dos 440 pacientes, a doença permaneceu estável em 408 pacientes, com estabilização de $98 \%$ das lesões e 50 dos 408 pacientes (12,25\%), manisfetaram uma ou duas recidivas durante o tratamento.

Dessa forma, os estudos realizados com a utilização da terapia por MPO, isoladamente ou de forma combinada em um grupo de pacientes levando em consideração a concentração da substância, o tempo de uso e a recidiva da doença, geraram um levantamento de análises quanto ao maior nível de efetividade da estabilização e repigmentação das lesões de vitiligo, evidenciando que a terapia garante uma boa resposta ao ser usada de forma adequada (Figura 2).

O ensaio clínico realizado por Singh et al. (2014), para comparar a eficácia e a tolerância da minociclina oral versus o corticosteroide MPO no vitiligo ativo evidenciou que o tratamento é eficaz para interromper a atividade do vitiligo, dentre os 50 indivíduos que foram distribuídos em dois grupos, o primeiro grupo recebeu minociclina $100 \mathrm{mg}$ por via oral/dia e o segundo recebeu dexametasona $2,5 \mathrm{mg} /$ dois dias contínuo por semana. $\mathrm{O}$ estudo também revelou que ambos os grupos tiveram 
diminuição no escore VIDA, no primeiro grupo de 4,0 para 1,64 \pm 0,86 (p <0,001), no segundo de 4,0 para 1,68 \pm 0,69 (p $<0,001)$, portanto não houve diferença estatisticamente significativa na pontuação VIDA, para ambos $(p=0,60)$, como mostra a Figura 2.

Figura 2. Fotografias da região ventral do antebraço de paciente com vitiligo vulgar antes (a) e depois (b) do tratamento.

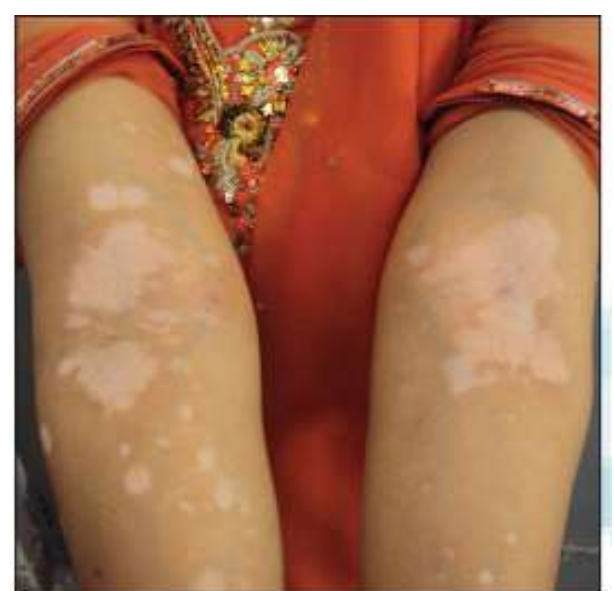

(a)

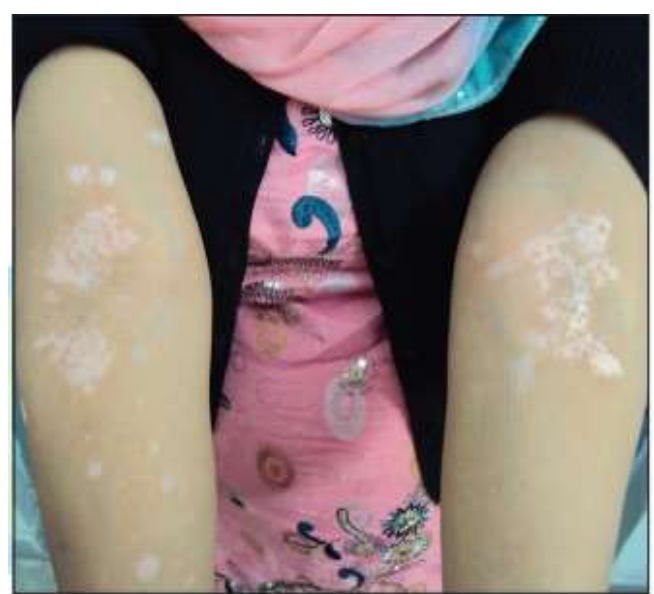

(b)

Fonte: Singh et al. (2014)

Lee et al. (2016) publicaram um estudo retrospectivo com o objetivo de avaliar a eficácia e tolerância da metilprednisolona associada a fototerapia UVB-NB no vitiligo não segmentar. Nesse estudo, 32 pacientes receberam tratamento com metilprednisolona (MPO) na dose de $0,5 \mathrm{mg} / \mathrm{Kg} /$ dia, dois dias consecutivos por semana e fototerapia UVB-NB por pelo menos três meses, sendo avaliados por mais de seis. A progressão do vitiligo cessou em todos os indivíduos, sendo que 19 deles $(59,4 \%)$ tiveram repigmentação $>25 \%$ das lesões, $13(40,6 \%)$ alcançaram repigmentação > 50\%. Segundo os autores, esse esquema de tratamento pareceu ser eficaz na interrupção da atividade e na repigmentação das lesões, apresentando efeitos adversos mínimos.

A publicação de um estudo de corte retrospectivo em paciente com vitiligo ativo realizado por Tovar -Garza et al. (2019) para testar a eficácia e tolerância de MPO com dexametasona adicionada à fototerapia UVB-NB e corticosteroides tópicos revelou que a área de superfície corporal (ASC) comprometida do grupo A, que receberam MPO de dexametasona 4,0 $\mathrm{mg} / 2$ dias consecutivos por semana, fototerapia com UVB-NB e creme de clobetasol 0,05\% foi maior do que o grupo B (p = 0,02), os quais indicavam indivíduos que não queriam receber MPO ou tinham contraindicações. A cessação da atividade foi alcançada em 23 dos 25 pacientes (92\%) no grupo A, em comparação com 8 dos 15 pacientes (53\%) no grupo B. Segundo os autores, esse estudo sugere que a adição de dexametasona MPO demostrou eficácia em retardar a progressão da doença e que a maioria deles não apresentou efeitos adversos.

Patra et al. (2019) apresentaram um ensaio clínico randomizado para comparar a eficácia e tolerância da betametasona MPO versus azatioprina oral no vitiligo rapidamente progressivo mostrando uma divisão em dois grupos, dentre os 55 adultos incluídos. Logo, o grupo A, com 28 indivíduos, recebeu MPO de betametasona 5,0 mg por dois dias consecutivos por semana, o grupo B com 27 indivíduos receberam azatioprina 50,0 mg, 2 comprimidos ao dia, durante seis meses. Dois participantes do grupo A alcançaram uma repigmentação de $20 \%$, outros dois participantes alcançaram de 10 a $20 \%$ de repigmentação e nove de 5 a 10\%, enquanto no grupo B apenas dois pacientes alcançaram uma repigmentação de 10 a $20 \%$. Diante dos resultados evidenciados, os autores concluíram que ambos os fármacos são alternativas de tratamento para esse tipo de vitiligo, entretanto a repigmentação das lesões alcançada pela betametasona MPO parece ser maior do que a alcançada pela azatioprina.

Assim, tais estudos mostraram que o corticosteroide utilizado com maior prevalência foi a dexametasona pelo fato de 
estabilizar o vitiligo, ou seja, interromper a atividade da doença, já que os corticosteroides atuam inibindo a inflamação e modulando o sistema imune contra o ataque aos melanócitos, permitindo que não ocorra a progressão da atividade da doença, sendo considerado um tratamento muito eficaz. Outros corticosteroides como a metilpredinisolona, metotrexato, minociclina, clobetasol, betametasona e azatioprina contribuíram também na estabilização da doença, porém esses não foram utilizados com uma frequência maior comparado à dexametasona.

\subsection{Fotobiomodulação}

O termo "Terapia com luz em baixas intensidades" (Low-Level Light Therapy - LLLT) é, atualmente, o termo que melhor define a "Terapia por Fotobiomodulação" (do inglês, Photobiomodulation Therapy - PBMT) (Khan \& Arany, 2016). Historicamente, desde que os efeitos clínicos da PBMT puderam ser observados, estudos laboratoriais vêm sendo desenvolvidos buscando elucidar os mecanismos celulares e moleculares que a radiação causa nos tecidos celulares. Assim, tais estudos propõem que a elucidação da absorção da luz dar-se-á devido à fotorreceptores endógenos, denominados cromóforos, localizados na superfície mitocondrial e no interior das células (Karu, 1986).

Nesse sentido, sabe-se que ocorre uma reação fotobiológica quando os fótons incidentes sobre as células são absorvidos. Inicialmente isso leva a mudanças diretamente relacionadas à configuração molecular do fotorreceptor, tais alterações são denominadas reações primárias. Posteriormente, esse processo é acompanhado por alterações em uma série de sinais e funções celulares, as quais compõem as reações secundárias, as quais constituem cascatas moleculares, incluindo a sinalização mitocondrial retrógrada, que consiste na comunicação intracelular da mitocôndria com o núcleo, influenciando diversas atividades celulares (De Freitas \& Hamblin, 2016; Hamblin, 2017).

Por isso, as terapias utilizando a fotobiomodulação são cada vez mais empregadas devido evidências indicarem sua influência diretas na síntese e na expressão de diversas citocinas, fatores de crescimento e fatores de transcrição, tais como o fator de transformação do crescimento beta (Transforming growth factor betta - TGF- $\beta$ ), o fator de crescimento epidérmico (Epidermal growth fator - EGF), o fator de crescimento do endotélio vascular (Vascular endothelial growth fator - VEGF), o fator de crescimento de fibroblastos (Fibroblast growth fator - FGF) e o fator Nuclear Kappa B (Nuclear Factor - Kappa b). Esses fatores exercem efeitos em fibroblastos, queratinócitos, células endoteliais e neutrófilos promovendo sua proliferação, migração e auxiliando no processo de reparo tecidual (Arany et al., 2014; Chen et al., 2011; Fushimi et al., 2012).

\subsubsection{Revisão de fototerapias}

O Quadro 2 mostra um comparativo das respostas ao tratamento de diferentes tipos de fototerapias, UVA, UVB-NB, UVB, associação do psoraleno +UVA (PUVA) e Excimer laser (308 nm).

Quadro 2. Resposta ao tratamento para quatro tipos de modalidades de fototerapia pesquisadas.

\begin{tabular}{|c|c|c|c|c|}
\hline Terapia & Total de pacientes & \multicolumn{3}{|c|}{ Pacientes tratados (\%) } \\
\cline { 3 - 5 } & & Boa Resposta & Resposta fraca & $\begin{array}{c}\text { Não completou o } \\
\text { tratamento }\end{array}$ \\
\hline UVB-NB* & 19 & $14(74 \%)$ & $4(21 \%)$ & $1(5 \%)$ \\
\hline $\begin{array}{c}\text { UVA e UVB } \\
\text { combinados }\end{array}$ & 39 & $26(67 \%)$ & $8(21 \%)$ & $4(10 \%)$ \\
\hline $\begin{array}{c}\text { Excimer laser (308 } \\
\text { nm) }\end{array}$ & 19 & $10(53 \%)$ & $8(42 \%)$ & $1(5 \%)$ \\
\hline PUVA** & 25 & $13(52 \%)$ & $9(36 \%)$ & $3(12 \%)$ \\
\hline
\end{tabular}

*UVB-NB: ultravioleta B de banda estreita; ** PUVA: psoraleno+UVA. Fonte: Adaptado de Koh, Mok e Chong (2015). 
Koh, Mok e Chong (2015) realizaram uma revisão retrospectiva com pacientes menores de 16 anos de idade com diagnóstico clínico de vitiligo, tratados com fototerapia, no National Skin Centre, em Cingapura, durante um período de 5 anos. Em termos de graduação de melhora do vitiligo, foi considerado a melhora como boa, aquela estimada em pelo menos $50 \%$ de repigmentação avaliada pelo paciente e pelo médico. A resposta ruim (baixa repgmentação) foi avaliada como obtendo menos de $50 \%$ de repigmentação. Nesse estudo, foram identificados 71 pacientes asiáticos com idades entre 5 e 15 anos quando foram submetidos à fototerapia, ou seja mais da metade dos pacientes apresentaram vitiligo generalizado e mais de um terço tinham vitiligo segmentar. A duração da doença variou de 2 meses a 12 anos. Desses, 39 pacientes foram diagnosticados com vitiligo generalizado (55\%), 27 com vitiligo segmentar (38\%), 3 com envolvimento da ponta dos lábios (4\%) (apenas locais acrais e lábios), e 2 com uma única lesão (3\%).

Koh, Mok e Chong (2015) realizaram estudo com fototerapia UVB-NB (ultravioleta B de banda estreita), no qual dos 19 pacientes foram tratados (17 apresentaram vitiligo vulgar e 2 vitiligo segmentar). Do total, 14 pacientes relataram boa resposta (74\%), já 4 pacientes comunicaram resposta ruim $(21 \%)$ e 1 e não completaram o tratamento (5\%). Nove pacientes relataram efeitos colaterais leve, sendo o eritema mais comum (observado em seis pacientes). Outros efeitos colaterais menos comuns incluem coceira e bolhas. A Figura 3 mostra o antes e depois do tratamento com fototerapia UVB-NB de uma paciente com vitiligo.

Figura 3. Paciente com vitiligo na região abdominal (a) antes e (b) após tratamento com fototerapia ultravioleta B de banda estreita (UVB-NB).

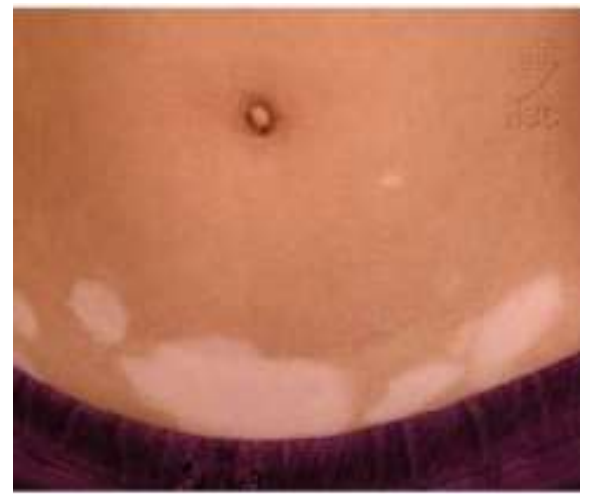

(a)

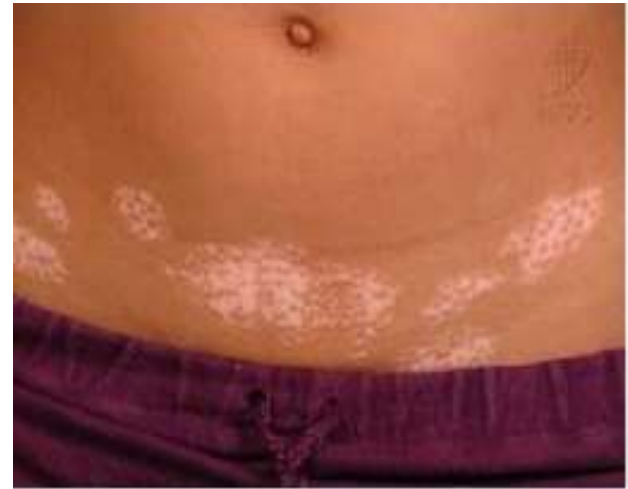

(b)

Fonte: Koh, Moh \& Chong (2015).

\subsubsection{Kelina}

O Quadro 3 mostra os principais estudos realizados com kelina para tratamento do vitiligo. Um estudo com 60 pacientes tratados com $100 \mathrm{mg}$ de kelina ou placebo juntamente com 15 minutos de exposição natural ao sol diariamente. Após 4 meses de tratamento, $16,6 \%$ dos pacientes apresentavam 90-100\% de repigmentação. Desses 23,3\% apresentavam de 50-60\% de repigmentação e 36,6\% não responderam ao tratamento. Nenhuma repigmentação foi observada entre 30 pacientes controle (Abdel-Fattah et al., 1982). Hofer, Kerl e Wolf (2001) revisaram retrospectivamente os resultados de 28 pacientes tratados com fototerapia UVA associados a $100 \mathrm{mg}$ de kelina para vitiligo generalizado. Entre os pacientes que receberam pelo menos 3 meses de tratamento $41 \%$ demonstraram pelo menos $70 \%$ de repigmentação, entretanto houve relato de náusea por $29 \%$ dos pacientes. O acompanhamento de longo prazo estava disponível por até 9,2 anos (média de 3,3 anos) e não mostrou casos de dano actínico ou câncer de pele. 
Quadro 3. Estudos utilizando kelina no tratamento do vitiligo.

\begin{tabular}{|c|c|c|c|c|c|}
\hline $\begin{array}{c}\text { Autor / } \\
\text { Pesquisa }\end{array}$ & Intervenção & $\begin{array}{c}\mathrm{N}^{0} \mathrm{de} \\
\text { pacientes }\end{array}$ & $\begin{array}{c}\text { Duração } \\
\text { (meses) }\end{array}$ & Resultado primário & Efeitos adversos \\
\hline $\begin{array}{l}\text { (Abdel-Fattah } \\
\text { et al., 1982) } \\
\text { Duplo- cego- } \\
\text { controlada }\end{array}$ & $\begin{array}{c}\text { Kelina } \\
(100 \mathrm{mg}) \text { ou } \\
\text { placebo/ luz } \\
\text { solar natural }\end{array}$ & 60 & 4 & $\begin{array}{l}\text { 16,6\% com } 90-100 \% \text { de } \\
\text { repigmentação. } \\
23,3 \% \text { com } 50-60 \% \text { de } \\
\text { repigmentação } \\
\text { 36,6\% não responderam. } \\
\text { Sem repigmentação entre } \\
\text { controles de placebo. }\end{array}$ & $\begin{array}{c}\text { Não abordado no } \\
\text { estudo }\end{array}$ \\
\hline $\begin{array}{l}\text { Ortel et al. } \\
\text { (1988) } \\
\text { Não } \\
\text { controlado }\end{array}$ & $\begin{array}{l}\text { Kelina } \\
\text { (100mg) } \\
\text { (oral ou } \\
\text { tópico) / } \\
\text { UVA }\end{array}$ & 28 & 6 & $\begin{array}{c}41 \% \text { dos pacientes } \\
\text { alcançaram pelo menos } \\
70 \% \text { de repigmentação }\end{array}$ & $\begin{array}{l}\text { Transaminite } \\
\quad(28 \%) \\
\text { Náusea }(21 \%) \\
\text { Ortostase }(7 \%)\end{array}$ \\
\hline $\begin{array}{l}\text { Hofer et al. } \\
\quad(2001) \\
\text { Retrospectiva }\end{array}$ & $\begin{array}{c}\text { Kelina } \\
(100 \mathrm{mg}) / \\
\text { UVA }\end{array}$ & 28 & 3 & $\begin{array}{c}41 \% \text { dos pacientes } \\
\text { tinham pelo menos } 70 \% \\
\text { de repigmentação }\end{array}$ & Náusea $(29 \%)$ \\
\hline
\end{tabular}

Fonte: Autores.

Ortel, Tanew e Hönigsmann (1988) investigaram o uso de fototerapia UVA três vezes por semana junto com terapia oral $(\mathrm{n}=25)$ ou tópico $(\mathrm{n}=3)$ utilizando a kelina. Após 6 meses, $41 \%$ dos pacientes alcançaram $70 \%$ de repigmentação ou mais. Os efeitos colaterais incluíram elevações nas enzimas hepáticas (28\%), náuseas (21\%) e ortostase (7\%).

Dessa forma, faz-se necessário destacar que a kelina é um extrato da fruta mediterrânea Ammi visnaga (Hofer, Kerl \& Wolf, 2001), apresenta estrutura química semelhante aos psoralenos usados em PUVA, daí o interesse no uso dessa substância como uma alternativa mais segura aos psoralenos, uma vez que esses últimos são conhecidos por reticular DNA e por apresentarem propriedades mutagênicas (Ortel, Tanew \& Hönigsmann, 1988). Em contraste, a kelina não forma ligações cruzadas de DNA após a exposição as radiações UVA in vitro ou no interior das células de mamíferos, tornando-se, assim, uma opção mais segura no tratamento em associações com fototerapias.

De forma geral, sobre as fototerapias anteriormente expostas, notou-se que a fototerapia com maior poder de repigmentação cutânea foi da fototerapia UVB-NB, seguida por fototerapia direcionada combinando UVA e UVB; fototerapia com lâmpada de excímer de 308 nm e PUVA, respectivamente. Os efeitos colaterais relatados foram leves e incluíram coceira, descamação, eritema, dor, queimadura de sol, bolhas e fototoxicidade. No entanto, a modalidade fototerapia com PUVA, a qual associa o psoraleno e kelina, revelou promissores benefícios em relação à exposição da luz solar, mas o uso de kelina sistêmico pode ser limitado pelos seus potenciais efeitos colaterais. Consequentemente, o interesse da pesquisa mudou para a aplicação tópica de kelina encapsulada em lipossomas em combinação com fototerapia. Uma vez que a fototerapia PUVA com a utilização de substância fotosensibilizante (8-metoxi-psoraleno) mostrou- se mais eficaz, com percentual de repigmentação pouco acima de $50 \%$ na maioria dos casos, porém, a kelina possui percentual de repigmentação mais elevado em torno de $70 \%$ na maioria dos casos, sendo uma boa opção de tratamento.

\subsubsection{Laser HeNe}

O Quadro 4 mostra a utilização da terapia com o L.A.S.E.R - $\mathrm{H}_{\mathrm{e}} \mathrm{N}_{\mathrm{e}}$ (Amplificação da Luz por Emissão Estimulada de Radiação de baixa potência Hélio-Neônio) comparado ao tratamento com a radiação UVB para pacientes com vitiligo.

Macedo et al. (2012) selecionaram 22 pacientes, os quais foram divididos randomicamente em dois grupos: o grupo A $(\mathrm{n}=12)$, submetido à aplicação do L.A.S.E.R. $\mathrm{H}_{\mathrm{e}} \mathrm{N}_{\mathrm{e}}$ e o grupo $\mathrm{B}(\mathrm{n}=10)$, expostos a radiação ultravioleta $\mathrm{B}(\mathrm{UVB})$. Para $\mathrm{o}$ tratamento do grupo A foi utilizado o L.A.S.E.R. de baixa potência Hélio-Neônio $\left(\mathrm{H}_{\mathrm{e}} \mathrm{N}_{\mathrm{e}}\right)$, com comprimento de onda de 632,8 nm. A escolha do L.A.S.E.R. $\mathrm{H}_{\mathrm{e}} \mathrm{N}_{\mathrm{e}}$ se deu em função desse apresentar poder de penetração mais superficial, atingindo a epiderme 
e ativando a produção dos melanócitos e, consequentemente ativando a melanina. Já para o tratamento do grupo B, foi utilizado a radiaçaõ no ultravioleta, com lâmpada fluorescente com radiação B (UVB) na faixa de 290 a $320 \mathrm{~nm}$. Inicialmente, no grupo A, a área exposta foi de $4,87 \mathrm{~cm}^{2} \pm 3,70$ e, após a aplicação, foi de $4,15 \mathrm{~cm}^{2} \pm 2,89$, com diferença média de $0,72 \mathrm{~cm}^{2}(1,89)$. No grupo B, verificou-se que antes da aplicação a média foi de $5,36 \mathrm{~cm}^{2} \pm 6,36$ e, a após a aplicação, foi de $4,43 \mathrm{~cm}^{2} \pm 5,17$, com diferença média de $0,92 \mathrm{~cm}^{2} \pm 1,29$. Assim, ambos os grupos A e B mostraram resultados significativos na redução da mácula, com maior redução no grupo B.

Quadro 4. L.A.S.E.R $\mathrm{H}_{\mathrm{e}} \mathrm{N}_{\mathrm{e}}$ comparada com radiação UVB.

\begin{tabular}{|c|c|c|c|c|}
\hline $\begin{array}{c}\text { Autor / } \\
\text { Pesquisa }\end{array}$ & $\begin{array}{c}\text { Intervenção por } \\
\text { grupo }\end{array}$ & $\mathrm{N}^{0}$ de pacientes & Resultado primário & Efeitos adversos \\
\hline Macedo et al. (2012) & $\begin{aligned} \mathrm{GA}= & -\mathrm{L} \cdot \mathrm{A} \cdot \mathrm{S} . \mathrm{E} \cdot \mathrm{R} . \\
& \mathrm{H}_{\mathrm{e}} \mathrm{N}_{\mathrm{e}}, \\
\mathrm{GB}= & \text { Ultravioleta } \mathrm{B} \\
& (\mathrm{UVB})\end{aligned}$ & $\begin{array}{l}\mathrm{GA}=12 \\
\mathrm{~GB}=10\end{array}$ & $\begin{array}{c}\mathrm{G} \mathrm{A}=\text { a área de } 4,87 \mathrm{~cm}^{2} \\
\pm 3,70 \text { e, após a } \\
\text { aplicação, foi de } 4,15 \\
\mathrm{~cm}^{2} \pm 2,89, \text { com } \\
\text { diferença média de } 0,72 \\
\mathrm{~cm}^{2} 1,89 . \\
\mathrm{G} \mathrm{B}=\text { média era de } 5,36 \\
\mathrm{~cm}^{2} \pm 6,36 \text { e, após a } \\
\text { aplicação, foi de } 4,43 \\
\mathrm{~cm}^{2} \pm 5,17, \text { com } \\
\text { diferença média de } 0,92 \\
\mathrm{~cm}^{2} \pm 1,29 .\end{array}$ & $\begin{array}{l}\text { Sem efeitos } \\
\text { adversos } \\
\text { significativos }\end{array}$ \\
\hline
\end{tabular}

L.A.S.E.R= Light Amplification by Stimulated Emission of Radiation (Amplificação da Luz por Emissão Estimulada de Radiação); GA=Grupo a , GB=Grupo b Fonte: Autores.

Logo, a fototerapia utilizando L.A.S.E.R. HeNe, combinado com UVB se mostrou com poder de repigmentação maior de que na aplicação isolada de L.A.S.E.R. HeNe, o que reafirmou sua maior efetividade quando associado a outras terapias.

Nesse sentido, considera-se a fototerapia uma modalidade segura e eficaz para o tratamento do vitiligo, o que a coloca como terapia de primeira linha no Brasil e no mundo, sendo cada vez mais associada à outras terapias, a fim de, proporcionar interação com diferentes aspectos patogênicos da doença, para obtenção de resultados mais satisfatórios.

\subsection{Imunossupressores - Inibidor da Janus quinase (JAK)}

A patogênese do vitiligo envolve a destruição dos melanócitos via imunidade mediada por células, e estudos mostram que o IFN- $\gamma$ e as células T CD8 + desempenham um papel fundamental nesse processo (Rashighi \& Harris, 2015; Strassner et al., 2017). Por isso, os inibidores tópicos da Janus quinase estão atualmente em processo de testes clínicos em andamento por várias empresas farmacêuticas. Como exemplo, os que estão listados abaixo:

\subsubsection{Citrato de tofacitinibe}

O tofacitinibe é um inibidor JAK aprovado pelo órgão de Administração de Alimentos e Medicamentos dos EUA (FDA) em 2012, para o tratamento da artrite reumatoide moderada a grave. Na dermatologia, as formulações orais e tópicas de tofacitinibe demonstraram ser seguras e eficazes para o tratamento da psoríase em placas (Portis et al., 2013). Craiglow e King (2014) descreveram o sucesso do tofacitinibe oral no tratamento da alopecia universal. O Quadro 5 mostra trabalhos utiizando o fármaco citrato de tofacitinibe para o tratamento da repigmentação cutânea de pele em pacientes com vitiligo e possíveis efeitos adversos ao medicamento. 
Quadro 5. Resultado do uso de citrato de tofacitinibe para repigmentação cutânea em pacientes com vitiligo, e efeitos adversos ao medicamento.

\begin{tabular}{|c|c|c|c|c|}
\hline Autor & Pacientes & Método & Resultados & $\begin{array}{c}\text { Efeitos } \\
\text { adversos }\end{array}$ \\
\hline $\begin{array}{c}\text { (Craiglow \& King, } \\
\text { 2015) }\end{array}$ & 1 & $\begin{array}{c}5,0 \mathrm{mg} \text { de citrato } \\
\text { de tofacitinib oral } \\
\text { (Xeljanz®) }\end{array}$ & $\begin{array}{c}\text { Apenas 5\% de não } \\
\text { repigmentação em 5 } \\
\text { meses }\end{array}$ & Nenhum \\
\hline (Kim et al., 2018) & 1 & $\begin{array}{c}5,0 \mathrm{mg} \text { de citrato } \\
\text { de tofacitinib oral } \\
\text { (Xeljanz®) }+ \\
\text { UVB-NB* }\end{array}$ & $\begin{array}{c}75 \% \text { de } \\
\text { repigmentação em 3 } \\
\text { meses }\end{array}$ & Nenhum \\
\hline
\end{tabular}

*UVB-NB: ultravioleta B de banda estreita. Fonte: Autores.

Craiglow e King (2015) realizaram um estudo de caso onde o tratamento com citrato de tofacitinibe oral (Xeljanz®) foi iniciado com dose de 5,0 mg em dias alternados em uma paciente do sexo feminino de aproximadamente 50 anos de idade, apresentando diagnóstico de vitiligo generalizado. Após 3 semanas, a dose foi aumentada para 5,0 mg /dia (metade da dose aprovada para artrite reumatoide, que é 5,0 mg duas vezes ao dia). Após 2 meses de tratamento, houve repigmentação parcial da face e das extremidades superiores. Após 5 meses, a paciente apresentou repigmentação significativa da testa (Figura 4) e do dorso das mãos (Figura 5). Já as demais áreas acometidas pela doença demonstraram repigmentação parcial.

Entretanto, aproximadamente, 5,0\% da superfície corporal total permaneceu despigmentada. Entretanto, vale destacar que a paciente avaliada nesse estudo não desenvolveu efeitos adversos ao medicamento testado e apresentou bons resultados de repigmentação cutânea.

Figura 4. Fotografia da região da testa de paciente antes (a) e depois (b) de 5 meses de tratamento com citrato de tofacitinibe oral.

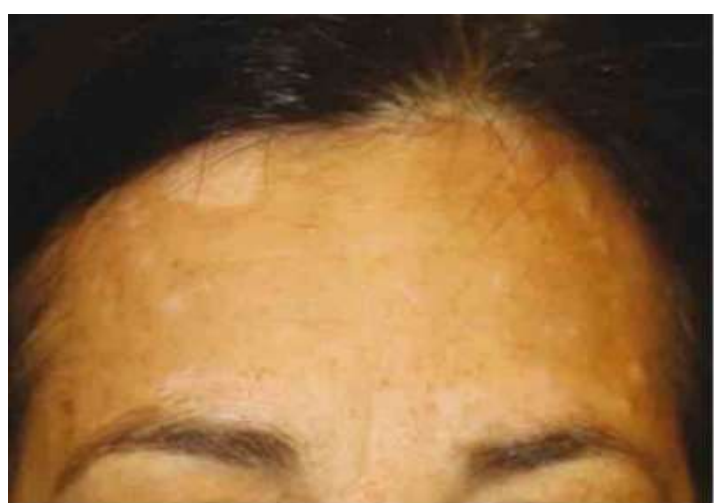

(a)

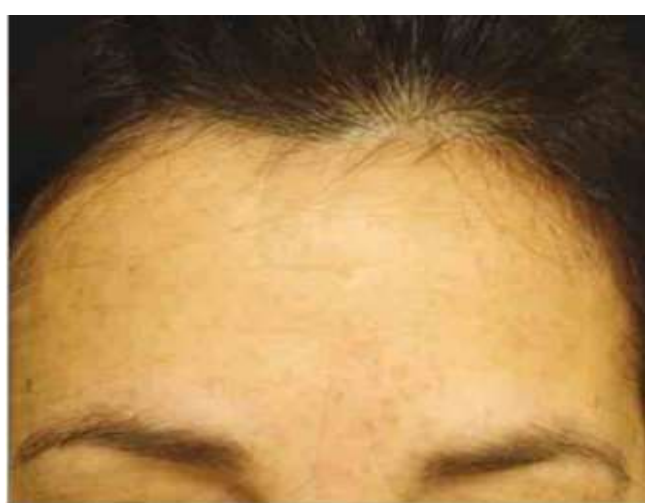

(b)

Fonte: Craiglow e King (2015). 
Figura 5. Fotografia do dorso das mãos de paciente antes (esquerda) e depois (direita) de 5 meses de tratamento com citrato de tofacitinibe oral.

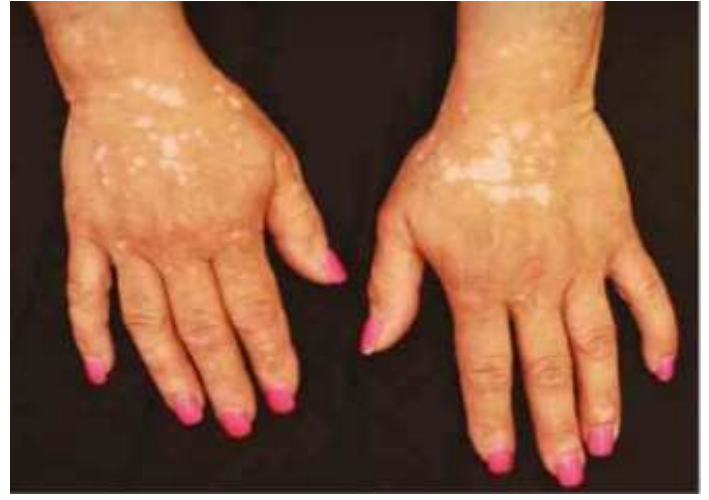

(a)

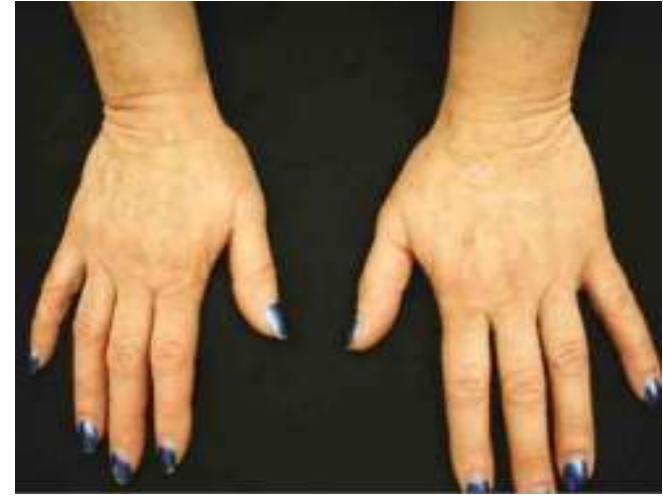

(b)

Fonte: Craiglow e King, (2015) e Craiglow e King, (2014).

Assim, tal pesquisa mostrou que as principais áreas de repigmentação foram aquelas áreas que têm maior exposição à luz solar (Kim et al., 2018). Os autores também utilizaram o citrato de tofacitinibe em associação a radiação UVB-NB em uma mulher de 30 anos com $75 \%$ do rosto despigmentado pelo vitiligo (Figura 6), bem como a presença de manchas brancas no pescoço, tórax, frente braços, mãos e canelas. O tratamento foi iniciado com tofacitinibe 5,0 mg duas vezes ao dia, associado a luz UVB-NB de corpo inteiro (400-500 $\mathrm{cm}^{-1}$ ) duas vezes por semana. Após 3 meses de tratamento, logo foi observado que havia uma quase repigmentação completa do rosto, ou seja, $75 \%$ de repigmentação do pescoço, tórax, antebraços e canelas, e apenas sardas mínimas nas mãos dorsais.

Figura 6. Antes (a) e 3 meses depois (b) do tratamento com tofacitinibe e UVB-NB.

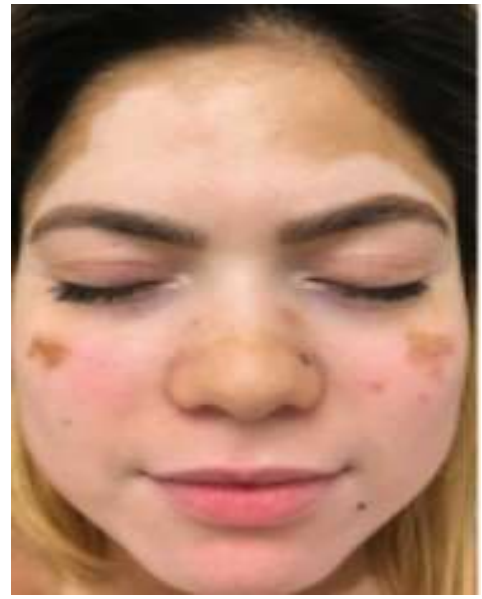

(a)

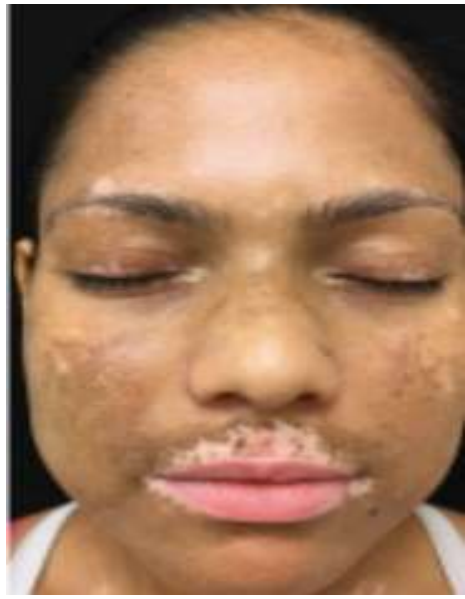

(b)

Fonte: Kim et al. (2018).

Nesse sentido, os tratamentos que envolvem o inibidor de Janus quinase estão se expandindo por ser uma técnica promissora e com resultados bastante satisfatórios, principalmente quando associados as fototerapias UVB-NB. Porém, ainda estão em fase de estudos e os reais efeitos dessas novas terapias pouco se conhece, o que se pode afirmar é que a curto prazo não produz efeitos colaterais e que seu custo é relativamente alto comparado às técnicas convencionais utilizadas.

Outro tratamento que se mostrou eficaz foi o creme de ruxolitinibe em diferentes concentrações para o tratamento do vitiligo. Em estudos de Rosmarin et al. (2020) realizaram um estudo com 157 pacientes adultos com idade entre 18 e 75 anos com vitiligo em 26 hospitais e centros médicos dos EUA, em 18 estados. Pacientes com 0,5\% ou mais de despigmentação facial 
e 3\% ou mais em outras regiões do corpo foram designados para receber o creme de ruxolitinibe 1,5\% duas vezes ao dia, 1,5\% uma vez ao dia, $0,5 \%$ uma vez ao dia ou $0,15 \%$ uma vez ao dia. Após 24 semanas os pacientes com $0,15 \%$ de ruxolitinibe foram re-randomizados para dose maiores por não mostrarem repigmentação superior a $25 \%$ em relação ao F-VASI. Os demais pacientes permaneceram com suas dose até o final da $52^{\circ}$ semana. De modo geral, a pesquisa revelou que todos os pacientes envolvidos até o final do tratamento apresentaram repigmentação em 50\%. Assim, segundo os autores o creme de ruxolitinibe pode ser uma opção de tratamento eficaz para pacientes com vitiligo. E as doses adotadas foram bem toleradas e os efeitos adversos graves não foram relatados.

\subsection{Antioxidantes}

Estudos recentes evidenciaram a relação do vitiligo com o estresse oxidativo em razão dos radicais livres produzidos no processo de síntese de melanina, com consequente degradação dos melanócitos, por uma irregularidade no mecanismo de defesa antioxidante (Ongenae, Van Geel \& Naeyaert, 2003). Sendo assim, trabalhar em aumentar a defesa antioxidante do organismo constitui um método promissor para o tratamento da patologia. Segundo Moser et al. (2019) antioxidantes são substâncias com a capacidade de retardar ou inibir a oxidação de lipídios dentre outras moléculas, evitando o início ou propagação das reações em cadeia de oxidação. Esta atividade em compostos fenólicos ocorre devido às suas atividades de óxido-redução, que desempenham ação na absorção, sequestro e neutralização de radicais livres, formando produtos estáveis.

\subsubsection{Mama-cadela}

A espécie vegetal Brosimum gaudichaudii é um arbusto pertencente à família Moraceae, comumente encontrada no cerrado brasileiro, popularmente conhecida por mama-cadela, conduru, maminha-de-cachorra, inharé, algodãozinho, mamicade-cadela, amoreira-do-mato e apê, apresenta uma ampla importância na medicina popular e no âmbito industrial. O interesse nas pesquisas envolvendo a mama-cadela se dá pela presença das furanocumarinas, psoraleno e bergapteno, ambas encontradas predominantemente nas cascas da raiz e cascas do caule da planta e também, no fruto maduro (Faria et al., 2015). Os principais compostos furanocumarínicos utilizados para o tratamento de doenças despigmentantes da pele são o psoraleno e o bergapteno, que podem ser obtidos através de extrações naturais ou sintetizados quimicamente através da condensação A, B 20 de um núcleo cumarínico com um anel furano e demais cadeias laterais (Zhou, Zhang \& Wang, 2014).

O quadro 6 mostra a eficácia de alguns estudos aplicando o psoraleno, principal metabólito presente na espécie Brosimum gaudichaidii (mama-cadela) em associação à radiaçaõ UVA.

Quadro 6. Estudos que comprovam eficácia da repigmentação após tratamento com associação psoraleno + radiação UVA (PUVA).

\begin{tabular}{|c|c|c|c|}
\hline Autor/ Ano & Tipo de estudo & $\mathbf{N}^{\mathbf{0}}$ de pacientes & Resultados \\
\hline $\begin{array}{c}\text { (Lerner, Denton \& } \\
\text { Fitzpatrick, 1953) }\end{array}$ & Estudo de casos & 9 & $\begin{array}{c}55 \% \text { melhora no quadro de } \\
\text { vitiligo }\end{array}$ \\
\hline $\begin{array}{c}\text { (Pathak, Pandey \& Singh, } \\
\text { 1984) }\end{array}$ & $\begin{array}{c}\text { Ensaio clínico } \\
\text { randomizado }\end{array}$ & 366 & $\begin{array}{c}45 \% \text { eficácia na } \\
\text { repigmentação da face e } \\
67 \% \text { de eficácia na } \\
\text { repigmentação da face e } \\
\text { pescoço. }\end{array}$ \\
\hline $\begin{array}{c}\text { (Kwok, Anstey \& Hawk, } \\
\text { 2002) }\end{array}$ & Metanálise & 97 & $\begin{array}{c}8 \% \text { repigmentação } \\
\text { completa, 60\% moderada e } \\
30 \% \text { mínima }\end{array}$ \\
\hline (Vussuki et al., 2006) & Estudo de casos & 28 & $\begin{array}{c}60 \% \text { dos pacientes com } \\
\text { repigmentação parcial }\end{array}$ \\
\hline
\end{tabular}

Fonte: Autores. 
O psoraleno é utilizado em associação à radiação ultravioleta (PUVA) com a finalidade de provocar a hiperpigmentação da pele em pacientes diagnosticados com vitiligo e psoríase (Pozetti, 2005). Doppalapudi et al. (2017) realizaram um estudo de metanálise que demostrou que o tratamento com PUVA deve ser indicado por no mínimo seis meses para aumentar a resposta ao tratamento. No entanto, é necessário que recorrentes avaliações sejam feitas para observar diferentes limitações como, por exemplo, dor, fototoxicidade, náusea ou eritema. Outros tratamentos têm sido incorporados paralelamente, a fim de aumentar o desempenho farmacológico e até mesmo substituí-lo por manejos com redução de respostas indesejadas. Frente a esse cenário, pesquisas com a utilização de plantas medicinais vêm apresentando crescimento considerável gerando menor custo e uma aceitabilidade favorável por parte dos usuários (Pinto et al., 2015).

Assim, a atividade antioxidante da mama-cadela foi analisada em um estudo realizado por Coutinho et al. (2019), no qual foi demostrado que sua atividade antioxidante é de 26,46\%, a mesma análise demonstrada por Land et al. (2017) resultou no valor de 28,85 $\pm 2,66$. Lima et al. (2014) relataram a presença de efeitos antioxidantes na casca da raiz e do caule da mamacadela e devido essa atividade ela vem sendo utilizada no tratamento do vitiligo. Por isso, a pesquisa empreendida propôs-se a realização da análise do teor de fenóis totais e a avaliação da atividade antioxidante da espécie Brosimum gaudichaudii para avaliar sua possível eficiência no combate ao estresse oxidativo, a qual demonstrou um valor considerável indicando que a espécie tem atuação importante contra os processos oxidativos que desencadeiam o vitiligo, podendo ser uma importante aliada em seu tratamento.

\subsubsection{Vitamina $\mathbf{E}$}

O quadro 7 mostra os resultados obtidos com PUVA e PUVA + Vitamina E. Akyol et al. (2002) realizaram estudos, onde trinta pacientes com vitiligo ativo, extenso e generalizado foram tratados (desses 16 mulheres e 14 homens), garantindo que os procedimentos de PUVA e terapia com vitamina $\mathrm{E}$ foram totalmente explicados. A média de idade foi de $29,92 \pm 15,70$ anos (variação de 14-60). Os fototipos de pele (seguindo a classificação de Fitzpatrick) foram os tipos II $(\mathrm{n}=4)$, III $(\mathrm{n}=22)$ e IV $(n=4)$. O primeiro grupo de pacientes foi tratado por seis meses com psoraleno associado a UVA $(n=15)$. O segundo grupo de pacientes foi tratado por seis meses com psoraleno associado a UVA e vitamina $\mathrm{E}$ (900 UI por dia por via oral) $(\mathrm{n}=15)$. Os pacientes foram avaliados após três e seis meses de tratamento. Os resultados foram classificados como ruins (sem melhora ou melhora inferior a $25 \%$ ), moderado (melhora entre $25 \%$ e $74 \%$ ) e bom (75\% ou mais), constatando que a vitamina E pode prevenir o sofrimento oxidativo resultante da terapia com PUVA, mas não afeta a melhora clínica das lesões de vitiligo.

Quadro 7. Relação pacientes com as terapias e respectivas respostas ao tratamento.

\begin{tabular}{|c|c|c|c|c|c|}
\hline \multirow{2}{*}{$\begin{array}{c}\text { Resposta a } \\
\text { terapia }\end{array}$} & \multicolumn{2}{|c|}{ Grupo 1 PUVA } & \multicolumn{2}{c|}{ Grupo 2 PUVA + Vit E } & \multirow{2}{*}{ Total } \\
\cline { 2 - 5 } & $\begin{array}{c}\text { Número de } \\
\text { pacientes }\end{array}$ & $\%$ & $\begin{array}{c}\text { Número de } \\
\text { pacientes }\end{array}$ & $\%$ & \\
\hline Boa (n) & 6 & 40,00 & 9 & 60,00 & 15 \\
\hline Moderada (n) & 4 & 26.66 & 3 & 20,00 & 7 \\
\hline Baixa (n) & 5 & 33.33 & 3 & 20,00 & 8 \\
\hline Total & 15 & 100,00 & 15 & 100,00 & 30 \\
\hline
\end{tabular}

Fonte: Autores.

\subsubsection{Ginkgo biloba}

Ginkgo biloba (GB) é uma erva tradicional chinesa que ganhou popularidade no tratamento de uma variedade de condições, incluindo doenças cardiovasculares, ansiedade, demência, degeneração macular e o vitiligo (Parsad, Dogra \& Kanwar, 2003; Szczurko \& Boon, 2008). Parsad, Dogra e Kanwar (2003) conduziram um estudo duplo-cego de GB em 52 pacientes com vitiligo de disseminação lenta e limitada. Os pacientes foram tratados com $40 \mathrm{mg}$ de monoterapia com GB ou 
placebo três vezes ao dia, a interrupção da doença ativa foi observada em $80 \%$ versus $36,6 \%$ dos pacientes controle $(p=0,006)$. Com isso, $75 \%$ de repigmentação foi observada em $40 \%$ dos pacientes que tomaram GB em comparação com $9 \%$ dos pacientes controle. Notavelmente, todos os pacientes com vitiligo acrofacial apresentaram cessação da doença ativa (Quadro 8).

Quadro 8. Estudos utilizando o Ginkgo biloba no tratamento do vitiligo.

\begin{tabular}{|c|c|c|c|c|c|}
\hline $\begin{array}{c}\text { Autor/ } \\
\text { Pesquisa }\end{array}$ & $\begin{array}{c}\text { Intervenção } \\
\text { Oral dose }\end{array}$ & $\begin{array}{c}\mathrm{N}^{\circ} \text {. de } \\
\text { paciente } \\
\quad \mathrm{S}\end{array}$ & $\begin{array}{c}\text { Duraçãa } \\
\text { (meses) }\end{array}$ & Resultado primário & Efeitos adversos \\
\hline $\begin{array}{l}\text { (Parsad, Dogra \& } \\
\text { Kanwar, 2003) } \\
\text { Duplo-cego, } \\
\text { randomizado } \\
\text { controlado }\end{array}$ & $\begin{array}{c}\text { Ginkgo biloba } \\
\text { monoterapia } \\
\text { ou placebo/ } 40 \\
\text { mg três vezes } \\
\text { diariamente }\end{array}$ & 52 & 6 & $\begin{array}{l}\text { Cessação da doença ativa em } 80 \% \\
\text { dos pacientes que tomam Ginkgo } \\
\text { biloba vs. } 36,6 \% \text { dos pacientes } \\
\text { com placebo, e C } 75 \% \\
\text { repigmentação em } 40 \% \text { dos } \\
\text { pacientes vs. } 9 \% \text { Todos os } \\
\text { pacientes cessaram a progressão } \\
\text { da doença e apresentaram uma } \\
\text { melhora na pontuação média de } 5 \\
\text { a } 4,5 \text { no índice de pontuação da } \\
\text { área de vitiligo e repigmentação } \\
\text { média de } 15 \%\end{array}$ & Nenhum \\
\hline $\begin{array}{l}\text { (Szczurko et al., } \\
\text { 2011) } \\
\text { descontrolado }\end{array}$ & $\begin{array}{c}\text { Ginkgo biloba } \\
\text { monoterapia/ } \\
120 \mathrm{mg} \\
\text { diariamente }\end{array}$ & 12 & 3 & $\begin{array}{l}\text { Todos os pacientes cessaram a } \\
\text { progressão da doença e } \\
\text { apresentaram uma melhora na } \\
\text { pontuação média de } 5 \text { a } 4,5 \text { no } \\
\text { índice de pontuação da área de } \\
\text { vitiligo e repigmentação média de } \\
15 \%\end{array}$ & $\begin{array}{l}\text { Um caso de } \\
\text { distúrbio } \\
\text { gastrointestinal e } \\
\text { alteração em } \\
\text { coagulação. }\end{array}$ \\
\hline
\end{tabular}

Fonte: Autores.

Szczurko et al. (2011) trataram 12 pacientes com $60 \mathrm{mg}$ de GB duas vezes ao dia durante 12 semanas. Todos os pacientes cessaram a progressão da doença e demonstraram uma repigmentação média de $15 \%$ com base no Índice de Pontuação de Área de Vitiligo $(\mathrm{p}=0,021)$. No geral, a maior melhora foi na região do tronco e nas extremidades inferiores. Acredita-se que as propriedades anti-inflamatórias do GB estejam relacionadas a uma redução na atividade da ciclooxigenase e diminuição da liberação de IL-8 e fator de crescimento endotelial vascular (VEGF) em resposta ao TNF, uma vez que o estresse oxidativo desempenha um papel no vitiligo e as propriedades antioxidantes do GB também contribuam para o processo ativação dos melanócitos.

\subsubsection{Polypodium leucotomos}

O Quadro 9 mostra os estudos realizados com a espécie Polypodium leucotomos no tratamento do vitiligo, onde (N / D) significa dados não abordado no estudo, UVB-NB - região no ultravioleta B de banda estreita, PUVA - psoraleno associado a ultravioleta $\mathrm{A}$

Polypodium leucotomos é uma espécie vegetal nativa da América Central e está disponível como suplemento de saúde há 30 anos (Emanuel \& Scheinfeld, 2007). Seu extrato foi estudado para o tratamento de várias condições, como psoríase, melasma, danos causados pela radiação ultravioleta e também para vitiligo (Mohammad, 1989). 
Quadro 9. Estudos de Polypodium leucotomos oral no tratamento de vitiligo.

\begin{tabular}{|c|c|c|c|c|c|c|}
\hline $\begin{array}{l}\text { Autor /Tipo de } \\
\text { estudo }\end{array}$ & Intervenção & $\begin{array}{l}\text { Dose } \\
\text { Diária }\end{array}$ & $\begin{array}{c}\mathbf{N}^{\mathbf{o}} \text {. de } \\
\text { pacientes }\end{array}$ & $\begin{array}{c}\text { Duração } \\
\text { (meses) }\end{array}$ & Resultado primário & $\begin{array}{l}\text { Efeitos } \\
\text { adversos }\end{array}$ \\
\hline $\begin{array}{l}\text { (Middelkamp-Hup et } \\
\text { al., 2007) } \\
\text { Duplo-cego, } \\
\text { randomizado } \\
\text { controlado }\end{array}$ & $\begin{array}{l}\text { Oral Polypodium } \\
\text { leucotomos- } \\
\text { UVB- NB } \\
\text { fototerapia } 2 \mathrm{x} \\
\text { semanal }\end{array}$ & $250 \mathrm{mg}$ & 50 & $6-7$ & $\begin{array}{c}\text { Repigmentação da } \\
\text { cabeça e pescoço em } \\
44 \% \text { dos pacientes que } \\
\text { ingeriram Polypodium } \\
\text { leucotomos em } \\
\text { comparação com } 27 \% \\
\text { dos controles. } \\
\text { Nenhuma diferença } \\
\text { significativa em } \\
\text { repigmentação para o } \\
\text { tronco ou extremidades }\end{array}$ & $\begin{array}{l}\text { Coceira leve } \\
\text { em } 40 \% \text { dos } \\
\text { pacientes que } \\
\text { tomaram } \\
\text { Polypodium } \\
\text { leucotomos vs. } \\
21 \% \text { dos } \\
\text { pacientes } \\
\text { controle }\end{array}$ \\
\hline $\begin{array}{l}\text { (Leone et al., 2006) } \\
\text { Randomizado, } \\
\text { controlado }\end{array}$ & $\begin{array}{l}\text { Fototerapia } \\
\text { UVB-NB 2x por } \\
\text { semana } \pm \text { oral } \\
\text { Polypodium } \\
\text { leucotomos }\end{array}$ & $480 \mathrm{mg}$ & 57 & 6 & $\begin{array}{c}\text { Repigmentação de } \\
47,8 \% \text { com } \\
\text { Polypodium } \\
\text { leucotomos e UVB-NB } \\
\text { vs. } 22 \% \text { com UVB-NB }\end{array}$ & N/D \\
\hline $\begin{array}{l}\text { (Reyes et al., 2006) } \\
\text { Duplocego, } \\
\text { randomizado } \\
\text { controlado }\end{array}$ & $\begin{array}{l}\text { Fototerapia } \\
\text { PUVA 3x por } \\
\text { semana } \pm \text { oral } \\
\text { diariamente } \\
\text { Polypodium } \\
\text { leucotomos }\end{array}$ & $720 \mathrm{mg}$ & 19 & 3 & $\begin{array}{l}50 \% \text { dos pacientes no } \\
\text { grupo Polypodium } \\
\text { leucotomos apresentou } \\
50 \% \text { de repigmentação } \\
\text { ou mais, vs. nenhum } \\
\text { do grupo placebo, } \\
\text { apresentou 50\% de } \\
\text { repigmentação }\end{array}$ & N/D \\
\hline $\begin{array}{l}\text { (Mohammad, 1989) } \\
\text { descontrolado } \\
\text { tentativas }\end{array}$ & $\begin{array}{l}\text { Oral Polypodium } \\
\text { leucotomos / } \\
\text { exposição solar } \\
\text { durante meses de } \\
\text { primavera / } \\
\text { verão }\end{array}$ & $360 \mathrm{mg}$ & 22 & 5 & $\begin{array}{c}\text { Todos os pacientes } \\
\text { tiveram repigmentação } \\
\text { completa }\end{array}$ & N/D \\
\hline
\end{tabular}

Fonte: Autores.

Middelkamp-Hup et al. (2007) investigaram o uso de P. leucotomos associado a UVB-NB para tratamento do vitiligo em 50 pacientes, os quais receberam $250 \mathrm{mg}$ de extrato $P$. leucotomos três vezes ao dia ou placebo, junto com duas sessões semanais de UVB-NB. Após 25-26 semanas, a repigmentação da cabeça e pescoço ocorreu em 44\% dos pacientes que utilizaram o extrato de $P$. leucotomos em comparação com $27 \%$ do grupo controle $(\mathrm{p}=0,06)$. Portanto, nenhuma diferença significativa foi observada na repigmentação do tronco ou extremidades desses pacientes. Já o benefício mais pronunciado ocorreu em pacientes com os tipos de pele mais clara, provavelmente refletindo P. Leucotomos na prevenção mediada de dano oxidativo, uma vez que a pele mais clara tem menos capacidade antioxidante inerente.

Leone et al. (2006) realizaram um estudo, no qual inscreveram 57 pacientes com vitiligo generalizado para receber fototerapia UVB-NB duas vezes ao dia $480 \mathrm{mg}$ de $P$. leucotomos diariamente. Após 6 meses, 47,8\% dos pacientes responderam ao tratamento no P. leucotomos e grupo UVB-NB versus $22 \%$ com UVB-NB isolado.

Reyes et al. (2006) examinaram o uso de P. leucotomos em combinação com psoraleno e ultravioleta A (PUVA) e 8metoxipsoraleno, 19 pacientes foram randomizados para receber PUVA associado ao P. leucotomos ou placebo. Após 12 semanas, metade dos pacientes no grupo que utilizaram o $P$. leucotomos demonstrou $50 \%$ de repigmentação ou mais, enquanto nenhum dos pacientes no grupo de placebo atingiu 50\% de repigmentação. No início do estudo, as amostras de sangue mostraram que os pacientes com vitiligo tinham expressão aumentada de CD25 e HLA-DR e diminuiu a expressão de células CD8, CD45RO nos pacientes tratados com P. leucotomos, mas não em pacientes do grupo controle. Assim, houve uma normalização de linfócitos, sugerindo o efeito imunomodulador sugerido pelo P. leucotomos (Middelkamp-Hup et al., 2007), mostrando-se eficaz para modular a imunidade celular e promovendo um ambiente de citocinas anti-inflamatórias. 


\section{Conclusão}

Diante do exposto, diversos fatores apontam as características principais de cada uma das terapias mencionadas nesse trabalho, como o uso de corticosteroides no tratamento do vitiligo mostrou-se eficaz, em especial na sua estabilização. No entanto a eficiência deles quanto à repigmentação foi baixa, porém avaliando-se o valor econômico, essa terapia é considerada uma alternativa, devido sua viabilidade econômica. Já a terapia utilizando a fotobiomodulação, em associação as radiações UVA, UVB, UVB-NB e PUVA, em praticamente todos os casos, mostraram efeitos potencializados. Além de apresentar resultados relevantes de repigmentação quando administrados tanto isolados, quanto em associação. Vale destacar que a Kelina mostrou resultados igual ou superior a $70 \%$ de repigmentação em todos os estudos encontrados. Já os imunossupressores que tratam da Janus quinase, quando associados as fototerapia, mostraram-se bastantes promissores, com resultados de repigmentação total ou acima de 75\%. Dos antioxidantes naturais, a espécie vegetal Brosimum gaudichaudii (mama-cadela) apresentou destaque com repigmentação acima de $45 \%$ e por possuir interações sinérgicas, entre os efeitos antioxidantes e fotossensibilizantes. Nesse sentido, tornando-se uma opção de terapia, uma vez que é oriunda de fonte natural e renovável sem exigir alto índice de processamento, não menos importante, para o tratamento do vitiligo. Nessa senda, os protocolos apresentados para o tratamento do vitiligo mostraram-se mais eficazes quando associados com as fototerapias UVB-NB e UVB, demonstrando que as fototerapias são as principais técnicas atualmente utilizadas em associação no auxílio e na potencialização dos seus efeitos. Logo, um dos fatores que apontam melhores rendimentos quanto à associação com as fototerapias é que elas possuem comprimentos de ondas diferentes e abordam camadas específicas da pele, uma vez que os raios UVB atingem a camada epidérmica, onde se localiza a maior quantidade de melanócitos, portanto alcançando os melhores resultados. Outro fator importante, é que a utilização da fotobiomodulação controla a resposta imune que, no caso dos portadores de vitiligo, é desregulada.

Nessa senda, esse trabalho mostra-se uma área bastante promissora que precisa ser aprofundada, principalmente, na busca de novas e promissoras terapias no tratamento do vitiligo, como proteínas sinalizadoras da destruição dos melanócitos, prevenindo o aparecimento das manchas hipocrômicas ou de terapias estimulatórias da expressão do GLI1, um candidato a gene associado as células-tronco, o qual é positivamente regulado em melanócitos capturados da protuberância de vitiligo tratado com UVB-NB em comparação com a protuberância de vitiligo não tratado.

\section{Referências}

Abdel-Fattah, A., Aboul-Enein, M. N., Wasset, G. M., \& El-Menshawi, B. S. (1982). Uma abordagem para o tratamento do vitiligo por khellin. Dermatology, 165 (2), 136-140.

Akyol, M., Celik, V. K., Ozcelik, S., Polat, M., Marufihah, M., \& Atalay, A. (2002). The effects of vitamin E on the skin lipid peroxidation and the clinical improvement in vitiligo patients treated with PUVA. EJD, 12(1), 24-26.

Arany, P. R. et al. (2014) Photoactivation of Endogenous Latent Transforming Growth Factor. Directs Dental Stem Cell Differentiation for Regeneration. Science Translational Medicine, 6 (238), 238ra69-238ra69.

Barona, M. I., et al. (1995) An epidemiologic case-control study in a population with vitiligo. Journal of the American Academy of Dermatology, 33 (4), 621625 .

Birlea, S. A., et al. (2017) Trends in Regenerative Medicine: Repigmentation in Vitiligo Through Melanocyte Stem Cell Mobilization. Medicinal Research Reviews, 37 (4), 907-935.

Craiglow, B. G., \& King, B. A. (2014). Killing two birds with one stone: oral tofacitinib reverses alopecia universalis in a patient with plaque psoriasis. The Journal of investigative dermatology, 134(12), 2988.

Craiglow, B. G., \& King, B. A. (2015). Tofacitinib citrate for the treatment of vitiligo: a pathogenesis-directed therapy. JAMA dermatology, 151(10), 1110-1112.

Cunha, P. R., Scabine Pessotti, N., Bonati Mattos, C., \& Salai, A. F. (2017). New approach in the treatment of refractory vitiligo: CO2 laser combined with betamethasone and salicylic acid solution. Dermatologic therapy, 30(1), e12410.

Cupertino, F., Niemeyer-Corbellini, J. P., \& Ramos-e-Silva, M. (2017). Psychosomatic aspects of vitiligo. Clinics in dermatology, $35(3), 292-297$.

De Freitas, L. F., \& Hamblin, M. R. (2016) Proposed Mechanisms of Photobiomodulation or Low-Level Light Therapy. IEEE Journal of Selected Topics in 
Quantum Electronics, 22 (3), 348-364.

Doppalapudi, S., Jain, A., Chopra, D. K., \& Khan, W. (2017). Psoralen loaded liposomal nanocarriers for improved skin penetration and efficacy of topical PUVA in psoriasis. European journal of pharmaceutical sciences, 96, 515-529.

Dos Santos, L. G. D. J., Coutinho, A. M., Damasceno, E. M. A., \& Soares, N. Z. D. (2019). Determinação dos fenóis totais e da atividade antioxidante da Brosimum gaudichaudii. Brazilian Journal of Health and Pharmacy, 1(3), 28-33.

Emanuel, P., \& Scheinfeld, N. (2007). Uma revisão do reparo de DNA e possíveis adjuvantes de reparo de DNA e antioxidantes naturais selecionados. Jornal online de dermatologia, 13 (3).

Estrela, C. (2018). Metodologia científica: ciência, ensino, pesquisa. Artes Médicas.

Ezzedine, K., Sheth, V., Rodrigues, M., Eleftheriadou, V., Harris, J. E., Hamzavi, I. H., \& Pandya, A. G. (2015). Vitiligo is not a cosmetic disease. Journal of the American Academy of Dermatology, 73(5), 883-885.

Faria, R. A. P. G., et al. (2015) Fenologia de Brosimum gaudichaudii trÉcul. (Moraceae) no cerrado de mato grosso. Ciencia Florestal, 25 (1), 67-75.

Fushimi, T., et al. (2012) Green light emitting diodes accelerate wound healing: Characterization of the effect and its molecular basis in vitro and in vivo. Wound Repair and Regeneration, 20 (2), 226-235.

Gonçalves, J. A. B. (2019). Avaliação dos protocolos para abordagem de vitiligo: Síntese de evidências. UNILUS Ensino e Pesquisa, 16(42), 97-111.

Hamblin, M. R. (2017). Mechanisms and applications of the anti-inflammatory effects of photobiomodulation. AIMS Biophysics, 4 (3), 337-361.

Hofer, A., Kerl, H., \& Wolf, P. (2001). Long-term results in the treatment of vitiligo with oral khellin plus UVA. European Journal of Dermatology, 11(3), 2259

Kanwar, A. J., Mahajan, R., \& Parsad, D. (2013). Low-dose oral mini-pulse dexamethasone therapy in progressive unstable vitiligo. Journal of cutaneous medicine and surgery, 17(4), 259-268.

Karu, T. I. (1986). Molecular mechanism of the therapeutic effect of low-intensity laser irradiation. Doklady Akademii nauk SSSR, 291 (5), 1245-9.

Khan, I., \& Arany, P. R (2016). Photobiomodulation Therapy Promotes Expansion of Epithelial Colony Forming Units. Photomedicine and Laser Surgery, 34 (11), 550-555.

Kim, S. R., Heaton, H., Liu, L. Y., \& King, B. A. (2018). Rapid repigmentation of vitiligo using tofacitinib plus low-dose, narrowband UV-B phototherapy. JAMA dermatology, 154(3), 370-371.

Koh, M. J. A., Mok, Z. R., \& Chong, W. S. (2015). Fototerapia para o tratamento do vitiligo em crianças asiáticas. Dermatologia pediátrica, 32 (2), $192-197$.

Kwok, Y. K. C., Anstey, A. V., \& Hawk, J. L. M. (2002). Psoralen photochemotherapy (PUVA) is only moderately effective in widespread vitiligo: a 10-year retrospective study. Clinical and experimental dermatology, 27(2), 104-110.

Land, L. R. B., Borges, F. M., Borges, D. O., \& Pascoal, G. B. (2017). Composição centesimal, compostos bioativos e parâmetros físico-químicos da mamacadela (Brosimum gaudichaudii Tréc) proveniente do Cerrado Mineiro. Demetra: alimentação, nutrição \& saúde, 12(2), 509-518.

Lee, J. T., \& Herlyn, M. (2012). MEK'ing o máximo da terapia de reativação de p53 no melanoma. Journal of Investigative Dermatology, 132 (2), $263-265$.

Leone, G., Pacifico, A., Iacovelli, P., Vidolin, A. P., \& Picardo, M. (2006). Tacalcitol and narrow-band phototherapy in patients with vitiligo. Clinical and Experimental Dermatology: Clinical dermatology, 31(2), 200-205.

Lerner, A. B., Denton, C. R., \& Fitzpatrick, T. B. (1953). Clinical and experimental studies with 8-methoxypsoralen in vitiligo. Journal of Investigative Dermatology, 20(4), 299-314.

Lima, M. R., Santos, P. D. A., Silveira, C. E. S., Palhares, D., \& Pereira, L. A. R. (2014). Cultivo in vitro de Brosimum gaudichaudii Tréc. (Moraceae). Revista Brasileira de Plantas Medicinais, 16, 462-466.

Macedo, A. C. B. D., Oliveira, C. F. D., Silva, E. C. M., \& Andrade, L. A. S. D. (2012). Efeitos da aplicação do LASER HeNe e do ultravioleta B no vitiligo. Fisioterapia em Movimento, 25, 481-488.

Middelkamp-Hup, M. A., Bos, J. D., Rius-Diaz, F., Gonzalez, S., \& Westerhof, W. (2007). Treatment of vitiligo vulgaris with narrow-band UVB and oral Polypodium leucotomos extract: a randomized double-blind placebo-controlled study. Journal of the European Academy of Dermatology and Venereology, 21(7), 942-950.

Mohammad, A. (1989). Vitiligo repigmentation with Anapsos (Polypodium leucotomos). International journal of dermatology, $28(7)$, 479-479.

Moser, C. D. S., et al. (2019) Caracterização de compostos bioativos e atividade antioxidante de amora-preta produzidas no oeste de Santa Catarina. In: A Face Multidisciplinar das Ciências Agrárias 4. [s.1.] Atena Editora.

Nunes, D. H., \& Esser, L. M. H. (2011) Perfil epidemiológico dos pacientes com vitiligo e sua associação com doenças da tireoide. Anais Brasileiros de Dermatologia, 86 (2), 241-248.

Ongenae, K., Van Geel, N., \& Naeyaert, J. M. (2003) Evidence for an Autoimmune Pathogenesis of Vitiligo. Pigment Cell Research, 16 (2), $90-100$.

Ortel, B., Tanew, A., \& Hönigsmann, H. (1988). Treatment of vitiligo with khellin and ultraviolet A. Journal of the American Academy of Dermatology, 18(4), 693-701. 
Parsad, D., Dogra, S., \& Kanwar, A. J. (2003). Quality of life in patients with vitiligo. Health and quality of life outcomes, 1(1), 1-3.

Pathak, P. C., Pandey, A. N., \& Singh, J. S. (1984). Overland flow, sediment output and nutrient loss from certain forested sites in the central Himalaya, India. Journal of Hydrology, 71(3-4), 239-251.

Patra, S., Khaitan, B. K., Sharma, V. K., \& Khanna, N. (2019). A randomized comparative study of the effect of betamethasone oral mini-pulse therapy versus oral azathioprine in progressive non-segmental vitiligo. Journal of the American Academy of Dermatology.

Pinto, M., Bani, G., \& Paiva, P. (2015). Mecanismo de indução de tolerância oral no tratamento de doenças autoimunes. Revista da UI_IP Santarém-Unidade de Investigação do Instituto Politécnico de Santarém.

Ports, W. C., Khan, S., Lan, S., Lamba, M., Bolduc, C., Bissonnette, R., \& Papp, K. (2013). Um ensaio randomizado de fase 2a de eficácia e segurança do inibidor tópico da J anus quinase tofacitinibe no tratamento da psoríase crônica em placas. British Journal of Dermatology , 169 (1), $137-145$.

Pozetti, G. L. (2005). Brosimum gaudichaudii Trecul (Moraceae): da planta ao medicamento. Revista de Ciências Farmacêuticas Básica e Aplicada, 26(3).

Rashighi, M., \& Harris, J. E. (2015) Interfering with the IFN- $\gamma /$ CXCL10 pathway to develop new targeted treatments for vitiligo. Annals of Translational Medicine, 3 (21), 1-5

Reyes, E., Jaén, P., de las Heras, E., de Eusebio, E., Carrión, F., Cuevas, J., \& Álvarez-Mon, M. (2006). Systemic immunomodulatory effects of Polypodium leucotomos as an adjuvant to PUVA therapy in generalized vitiligo: A pilot study. Journal of dermatological science, 41(3), 213-216.

Rosmarin, D. et al. (2020). Ruxolitinib cream for treatment of vitiligo: a randomised, controlled, phase 2 trial. The Lancet, 396 (10244), 110-120.

Singh, A., Kanwar, A., Parsad, D., \& Mahajan, R. (2014). Randomized controlled study to evaluate the effectiveness of dexamethasone oral minipulse therapy versus oral minocycline in patients with active vitiligo vulgaris. Indian Journal of Dermatology, Venereology and Leprology, 80(1), 29.

Singh, H., Kumaran, M. S., Bains, A., \& Parsad, D. (2015). A randomized comparative study of oral corticosteroid minipulse and low-dose oral methotrexate in the treatment of unstable vitiligo. Dermatology, 231(3), 286-290.

Souza, L. K. (2017) Abordagem sobre causas, qualidade de vida e tratamento de portadores de psoríase e vitiligo. [s.1.] Universidade Feevale.

Strassner, J. P. et al. (2017) Suction blistering the lesional skin of vitiligo patients reveals useful biomarkers of disease activity. Journal of the American Academy of Dermatology, 76 (5), 847-855.

Szczurko, O., \& Boon, H. S. (2008). A systematic review of natural health product treatment for vitiligo. BMC dermatology, 8(1), 1-12.

Szczurko, O., Shear, N., Taddio, A., \& Boon, H. (2011). Ginkgo biloba for the treatment of vitilgo vulgaris: an open label pilot clinical trial. BMC complementary and alternative medicine, 11(1), 1-9.

Tovar-Garza, A., Hinojosa, J. A., Hynan, L. S., \& Pandya, A. G. (2018). Addition of oral minipulse dexamethasone to narrowband ultraviolet B phototherapy and topical steroids helps arrest disease activity in patients with vitiligo. The British journal of dermatology, 180(1), $193-194$.

Vussuki, E., Ziv, M., Rosenman, D., \& David, M. (2006). Long-term effects of PUVA therapy on Israeli patients with vitiligo. Harefuah, 145(7), 483-5.

Whitton, M. E., Pinart, M., Batchelor, J., Leonardi-Bee, J., González, U., Jiyad, Z., Eleftheriadou, V., \& Ezzedine, K. (2015). Interventions for vitiligo. The Cochrane database of systematic reviews, (2).

Zhou, X., Zhang, G., \& Wang, L. (2014) Probing the binding mode of psoralen to calf thymus DNA. International Journal of Biological Macromolecules, 67, $228-237$. 